\title{
LETRAMENTO NA ERA DIGITAL: CONSTRUINDO SENTIDOS ATRAVESS DA INTERAÇÃO COM HIPERTEXTOS
}

\author{
Denise Bértoli Braga * \\ Ivan L.M. Ricarte **
}

\begin{abstract}
RESUMO: O texto discute letramento digital enfocando questōes específicas de produção e de leitura de hipertextos. Entendendo hipertexto como um produto de uma nova modalidade lingüística os autores discutem as diferentes etapas de um exercício de retextualização que visou transformar um texto impresso em um hipertexto. Em relaçāo à recepção de material hipertextual, o texto enfatiza a necessidade do desenvolvimento de novas estratégias de leitura e de uma visão mais esclarecida sobre o papel que a mediaçāo técnica, invisível na tela, que afeta os modos de construçāo de sentidos nas práticas letradas digitais.
\end{abstract}

PALAVRAS-CHAVE: letramento digital; hipertexto; autoria; leitura; cultura digital.

\section{Introdução}

uso do computador como ferramenta de comunicação
promove um conjunto de mudanças na linguagem. Alguns estudos têm enfatizado o surgimento de novos gêneros nos ambientes de interação abertos pela Internet (como blog, chat, fórum, e-mail). Outras pesquisas têm enfocado questões relativas à nova modalidade

" Departamento de Lingüística Aplicada - IEL/UNICAMP.

* Faculdade de Engenharia Elétrica e Computação - UNICAMP. 
BRAGA, Denise B. \& RiCARTE, Ivan L.M. Letramento na era digital: construindo...

lingüistica que surge no meio digital, como uma alternativa para superar os limites impostos pela tela para a leitura e uma forma de utilizar de modo funcional os diferentes recursos expressivos oferecidos pelo meio (Braga, 2003; Braga e Busnardo, 2004). Em relação às dificuldades para a leitura, um conjunto de fatores precisa ser considerado. A tela "imaterializa" o texto, deixando o leitor sem a noção do todo e sem algumas orientações visuais importantes que o auxiliam durante a leitura de textos impressos como, por exemplo, os limites de páginas. Além disso, a resolução atual de tela é pouco confortável para o processo de recepção, uma vez que demanda movimentos oculares mais amplos, que diminuem a velocidade de leitura. Essas dificuldades são ainda acentuadas pelo cansaço visual gerado pelo brilho da tela e pelo desconforto da posição fixa para a leitura. Esse conjunto de limites gera a necessidade de a informação ser disponibilizada de uma forma nova, mais eficiente para a construção de sentido nesse meio. Isso explica, em parte, as mudanças textuais mais evidentes no hipertexto: a quebra do texto em segmentos menores de informação interligados por links e a tendência a integrar outras modalidades expressivas ao texto verbal escrito.

Essa propensão a mudanças também pode ser parcialmente atribuída a fatores relativos ao processo de autoria. Os recursos digitais permitem importar e integrar em uma única máquina modos de expressão que foram socialmente construídos de forma relativamente paralela no contexto das diferentes mídias (Manovich, 2001). Aliada à criação de novas ferramentas técnicas, essa mobilização que atinge o próprio conceito de autor permite que usuários, relativamente leigos, passem a reproduzir, editar ou mesmo construir arquivos de som e imagem, uma atividade que antes exigia equipes altamente especializadas. $\mathrm{O}$ ato de produção textual na Internet, como aponta Kress(1998; 1999), deixa assim de ser restrito à construção de textos verbais, aproximando, cada vez mais, o papel do autor daquele tradicionalmente atribuído ao designer. $\mathrm{Na}$ 
Rev. ANPOLL, no 18, p. 59-82, jan./jun. 2005.

realidade, seria inadequado atribuirmos essa tendência acentuada de exploração de recursos multimodais no processo comunicativo apenas ao computador ou à Internet. A tendência é mais ampla, e o surgimento das novas tecnologias apenas a acelerou. A grande diferença a ser salientada, no entanto, é a de que uma parcela significativa da população letrada, principalmente os mais jovens, antes familiarizados com a interpretação de diferentes tipos de textos multimodais, deixou de ocupar só o lugar de leitor e passou a assumir o de autor ou co-autor, construindo textos que integram mais de uma linguagem. Outra mudança a ser ressaltada é o fato de a Internet permitir que textos produzidos por qualquer usuário possam ser acessados por uma audiência em larga escala. Essa participação social ampla cria uma nova dinâmica para o processo de mudança lingüística e para o surgimento de novos padrões interpretativos.

Alguns autores que abordam questões relativas à produção e ao uso de hipertextos vão além dessas questões das diferenças de modalidade mencionadas e buscam entendê-los como uma forma diferenciada de construção cultural: a cultura do banco de dados. Produto de um momento sócio-histórico marcado pelo acúmulo de informação, essa cultura não pode ser entendida dissociada dos recursos técnicos que viabilizam o registro e a recuperação de um volume enorme de informação.

O presente estudo reflete sobre esse conjunto de questões, indicando, inicialmente, alguns parâmetros lingüisticos e técnicos que precisam ser considerados na construção de hipertextos fechados. Estas reflexões têm como objeto de análise uma experiência de retextualização (transformação de um texto impresso linear em outro com formato hipertextual), conduzida pelos autores. A seguir, com base em Walton (2004), o texto discute a leitura para busca de informações na rede mundial de computadores (WWW), envolvendo portais e sites que integram conjuntos maiores de textos e hipertextos. Finalmente, são apresentadas algumas implicações que as questões 
Braga, Denise B. \& RicARTE, Ivan L.M. Letramento na era digital: construindo...

levantadas sobre a produção de material informativo para o meio digital trazem para a formação do hiperleitor.

\section{Hipertextos fechados: considerações sobre o processo de autoria}

No dominio da lingüística, as reflexões sobre hipertexto têm privilegiado questões relativas à leitura e apontado vantagens e problemas de naturezas muito distintas, dificultando uma compreensão mais clara sobre as possibilidades do uso de hipertexto nas práticas letradas digitais. Esse problema, contudo, talvez seja gerado pela natureza genérica do próprio termo hipertexto, que, desde a sua origem, tem sido sistematicamente utilizado de forma imprecisa. Mesmo descartando os casos freqüentes em que esse termo é erroneamente adotado para referir-se a textos lineares que foram meramente digitalizados para acesso em rede, é possivel constatarmos que esse conceito pode referir-se indiferentemente a realidades micro e macro-textuais. Snyder (1996) já aponta esse problema quando indica que há diferentes tipos de hipertexto: hipercads, hipertextos isolados, redes fechadas de hipertexto e redes abertas, como é o caso da WWW.

Uma possivel explicação para a abrangência conceitual do termo talvez possa ser resgatada da sua origem técnica. A noção de hipertexto surge não de reflexões lingüisticas, mas sim das reflexões sobre as diferentes possibilidades de recuperação de arquivos digitais viabilizadas por linguagens técnicas como HTML (a linguagem de marcação de hipertexto) e XML (a linguagem de marcação extensivel). De fato, todas as realidades textuais descritas acima contam com o auxílio dessas linguagens na criação da interface oferecida aos usuários.

Todavia se do ponto de vista técnico o uso abrangente do termo é justificado, do ponto de vista da produção e leitura de hipertextos 
Rev. ANPOLL, no 18, p. 59-82, jan./jun. 2005.

esse aspecto genérico pode ser problemático: algumas das afirmações propostas sobre a construção de conhecimento através de hipertextos talvez precisem ser restritas ao tipo de hipertexto em foco. Essa questão torna-se ainda mais complexa se considerarmos que os textos construídos para acesso via Internet ou via computador ainda têm adotado um formato híbrido, mais próximo dos textos impressos convencionais, nem sempre explorando a integração de modalidades expressivas ou tornando disponiveis caminhos de acesso múltiplos e flexiveis que têm sido apontados no plano teórico (Walton, 2004). Considerando esses problemas, no presente estudo optamos por refletir separadamente sobre hipertextos isolados (ou fechados) e redes hipertextuais abertas como a WWW.

\subsection{Comunicação em diferentes meios: um exercício de retextualização}

Mobilizando uma nova forma de saber, o hipertexto surge como produto de uma nova modalidade lingüística no meio digital, devido às possibilidades e aos limites do meio. Da mesma forma que textos orais transcritos não são adequados à leitura, o formato linear e seqüencial do texto impresso, transposto para o meio digital, também gera sérios problemas para a comunicação. No entanto, não podemos ignorar que essa é uma realidade textual muito nova e que temos ainda muita dificuldade de conceber textos que não sigam o padrão linear tradicional. Isso é verdade principalmente para a construção de sites pedagógicos, já que a forma de pensar científica se construiu fortemente ancorada na lógica argumentativa seqüencial dos textos impressos. Não é de se estranhar, portanto, que grande parte das discussões sobre hipertexto, como ilustram os estudos de Snyder (1996) e Landow (1997), tenham privilegiado o gênero literário que tende a ser mais flexivel em relação aos padrões de organização adotados. O uso crescente do computador como ferramenta de ensino nos conduz a uma outra direção e nos coloca frente à neces- 
Braga, Denise B. \& RicARTE, Ivan L.M. Letramento na era digital: construindo...

sidade de entendermos como se constroem textos de natureza informativa, direcionados à comunicação com fins acadêmicos no meio digital. Exercícios de retextualização, no sentido proposto por Marcuschi (2001), podem ser um caminho interessante para analisar os recursos de interatividade (Silva, 2000) e verificar como podem contribuir para o surgimento de formas alternativas de veicular informações.

Discutindo o processo de transformação de textos falados em textos escritos, Marcuschi (2001) esclarece que retextualização não se limita a uma mera transcodificação. Com relação à fala, transcodificar é passar um texto de sua realização sonora para a forma gráfica, sem interferir na natureza do discurso produzido do ponto de vista da linguagem e do conteúdo. Em contraste, retextualizar envolve operações complexas que interferem tanto no código como no sentido. Como ressalta o autor, a retextualização faz parte do nosso cotidiano na medida em que estamos constantemente adaptando nossos textos a uma intricada variação de estilos, registros, gêneros textuais ou meios de comunicação. Os esclarecimentos de Marcuschi levam-nos a considerar que exercícios de retextualização que envolvam a transformação de textos impressos em textos digitais podem ser um caminho promissor para refletirmos sobre a produção e leitura de hipertextos.

\subsection{A quebra da linearidade e seu impacto nos modos de organizar a informação}

Discutindo a retextualização de textos orais para textos escritos, Marcuschi (op.cit.) lista nove operações textuais-discursivas envolvidas. Algumas dessas operações estão diretamente relacionadas às convenções gráficas da escrita (pontuação, parágrafos); outras, relacionadas à edição textual (apagamento de repetições, reconstrução de estruturas truncadas, reordenação tópica e condensação das idéias, por exemplo). Das operações classificadas pelo autor, a que 
Rev. ANPOLL, $\mathrm{n}^{\circ}$ 18, p. 59-82, jan./jun. 2005.

envolve reorganização do tópico e da seqüência argumentativa textual é certamente a que se torna mais evidentemente problemática na passagem de textos impressos para hipertextos, já que tal passagem envolve quebra na linearidade textual. Considerando essa dificuldade, optamos por focalizar, na discussão que segue, apenas essa operação específica.

Nossas reflexões estão baseadas em um estudo exploratório conduzido com o intuito de explicitar nossas intuições sobre construção de hipertexto para ensino. Nossa experiência prévia com a construção de materiais digitais e reflexões teóricas sobre hipertexto orientaram este exercício de cunho prático. Embora o método adotado no estudo em questão seja fundamentalmente heurístico, ou seja, relativamente intuitivo, acreditamos que a experiência prática pode não só trazer questões interessantes sobre essa nova realidade, como também vir a nortear pesquisas futuras. Considerando que são poucos os trabalhos na área da linguagem que refletem sobre produção de hipertextos, dados relativos à produção textual podem trazer uma contribuição importante para repensarmos questões relativas à leitura e ao ensino do letramento digital.

Como objeto de retextualização elegemos uma reportagem publicada pela revista VEJA, intitulada "O corpo é o espelho da mente". ${ }^{1}$ O texto analisado tematiza o uso de técnicas orientais para cura de algumas doenças e relata resultados de pesquisas que apóiam a incorporação desse tipo de tratamento à medicina tradicional. Na discussão da passagem dessa matéria impressa para o formato hipertextual, algumas operações puderam ser discriminadas: segmentação das informaçōes textuais; introdução de redundância para tornar fragmentos coerentes; definição de associaçōes entre frag-

1 Esse material foi originalmente selecionado como parte de um estudo de dissertação de mestrado, em progresso da Faculdade de Engenharia Elétrica e Computação, intitulado Aplicação de metadados para a construção de hipertextos, de autoria de Alessandro Donaires Figueira, orientada pelos autores. 
BraGa, Denise B. \& RICARTE, Ivan L.M. Letramento na era digital: construindo...

mentos e de caminhos sugeridos para a leitura e escolhas das opções técnicas para a construção da estrutura de navegação.

Para refletir sobre a segmentação das informações textuais os autores realizaram isoladamente um exercício cujo objetivo é redistribuir as informações delimitadas no texto em segmentos menores, facilitando a leitura na tela. Os dois resultados obtidos indicaram que, apesar de algumas diferenças em relação ao recorte dos segmentos propostos, ambos os autores intuitivamente adotaram um critério de categorização temática. Considere-se, por exemplo, o seguinte parágrafo do texto original:

"Um dos maiores investigadores do poder da mente sobre a saúde é o cardiologista americano Herbert Benson, da Universidade Harvard, autor do livro Medicina Espiritual. Pesquisas conduzidas por ele mostram que, em média, $60 \%$ das consultas médicas poderiam ser evitadas, caso as pessoas usassem sua capacidade mental para combater naturalmente tensões que são causadoras de problemas fisicos. A meditação, demonstra Benson, figura entre as maneiras mais efetivas de fortalecer a mente. Meditar, no caso, não significa pensar detidamente sobre um determinado assunto ou aspecto da vida. Quer dizer justamente o contrário: não pensar em nada durante uma certa parte do dia. É dessa forma, esvaziando a mente das atribulações cotidianas, que os monges budistas tentam atingir o nirvana - aquele estado de absoluta suspensão do ego a través, do qual se consegue escapar das aflições que costumam tumultuar o cérebro da maioria das pessoas, prejudicando sua saúde. Para os seguidores de Buda, este é o supra-sumo do conhecimento e da felicidade."

Detectamos no fragmento selecionado três tipos de informação. Inicialmente, há uma apresentação de um estudioso sobre o assunto, cujo nome é citado mais algumas vezes ao longo do texto. Em seguida, há um relato sobre a natureza dos estudos realizados por ele. Finalmente, uma definição sobre a técnica terapêutica que, neste 
Rev. ANPOLL, nº 18, p. 59-82, jan./jun. 2005.

caso, é a meditação. Esse parágrafo foi, portanto, fragmentado em três segmentos:

Segmento 1 [Apresentação do pesquisador]: O cardiologista americano Herbert Benson, da Universidade Harvard, é o autor do livro Medicina Espiritual e um dos maiores investigadores do poder da mente sobre a saúde.

Segmento 2 [Estudos terapêuticos]: Pesquisas conduzidas por Benson mostram que, em média, 60\% das consultas médicas poderiam ser evitadas, caso as pessoas usassem sua capacidade mental para combater naturalmente tensões que são causadoras de problemas físicos. A meditação, demonstra Benson, figura entre as maneiras mais efetivas de fortalecer a mente.

Segmento 3 [Descrição de técnica]: Meditar não significa pensar detidamente sobre um determinado assunto ou aspecto da vida. Quer dizer justamente o contrário: não pensar em nada durante uma certa parte do dia. É dessa forma, esvaziando a mente das atribulações cotidianas, que os monges budistas tentam atingir o nirvana - aquele estado de absoluta suspensão do ego, através do qual se consegue escapar das aflições que costumam tumultuar o cérebro da maioria das pessoas, prejudicando sua saúde. Para os seguidores de Buda, esse é o supra-sumo do conhecimento e da felicidade.

Nesse exemplo, pode-se observar que o uso do pronome no parágrafo original ("Pesquisas conduzidas por ele") teve que ser substituido pelo nome, visto que, com a fragmentação, não haveria mais a imposição de que a leitura do segundo segmento fosse realizada logo após a leitura do primeiro segmento. Por outro lado, torna-se necessária a apresentação de Benson num segmento próprio, pois pode ser que o leitor, no processo de leitura não-linear, atinja uma referência a esse pesquisador sem ter passado pelos outros dois segmentos. Essa reintrodução de elementos redundantes, que normal- 
Braca, Denise B. \& Ricarte, Ivan L.M. Letramento na era digital: construindo...

mente deve ser eliminada no texto escrito, foi necessária na construção de vários segmentos do texto.

A segmentação do parágrafo descrita acima é ilustrativa do processo de retextualização realizado no texto como um todo. Neste exercício, uma análise inicial de conteúdo permitiu que os autores discriminassem várias categorias temáticas que aparecem distribuidas de forma imbricada ao longo do texto: uma, mais geral, sobre a relação corpo e mente; outras, mais especificas, versando sobre descrição de técnicas orientais, estudos terapêuticos envolvendo essas técnicas no tratamento de doenças específicas, benefícios à saúde observados na aplicação dessas técnicas, locais onde tais tratamentos poderiam ser encontrados e apresentações de indivíduos (pesquisadores que atuam nessa área). As relações entre os cinco primeiros tipos de segmentos podem ser observadas no mapa conceitual construído para representar esse texto (ver figura 1). Um mapa conceitual é uma estrutura na qual conceitos (representados pelos retângulos com cantos ovalados) estão ligados por associações (representadas pelas linhas que conectam os retângulos). Observe que a apresentação de indivíduos não seria bem representada nessa estrutura, pois caracteriza uma informação complementar que pode ocorrer em qualquer fragmento. Apesar de ser possivel indicar que indivíduos são citados, em quais fragmentos, a inclusão dessas associações tornaria a visualização do mapa mais carregada e de difícil compreensão. 
Rev. ANPOLL, n' 18, p. 59-82, jan./jun. 2005.

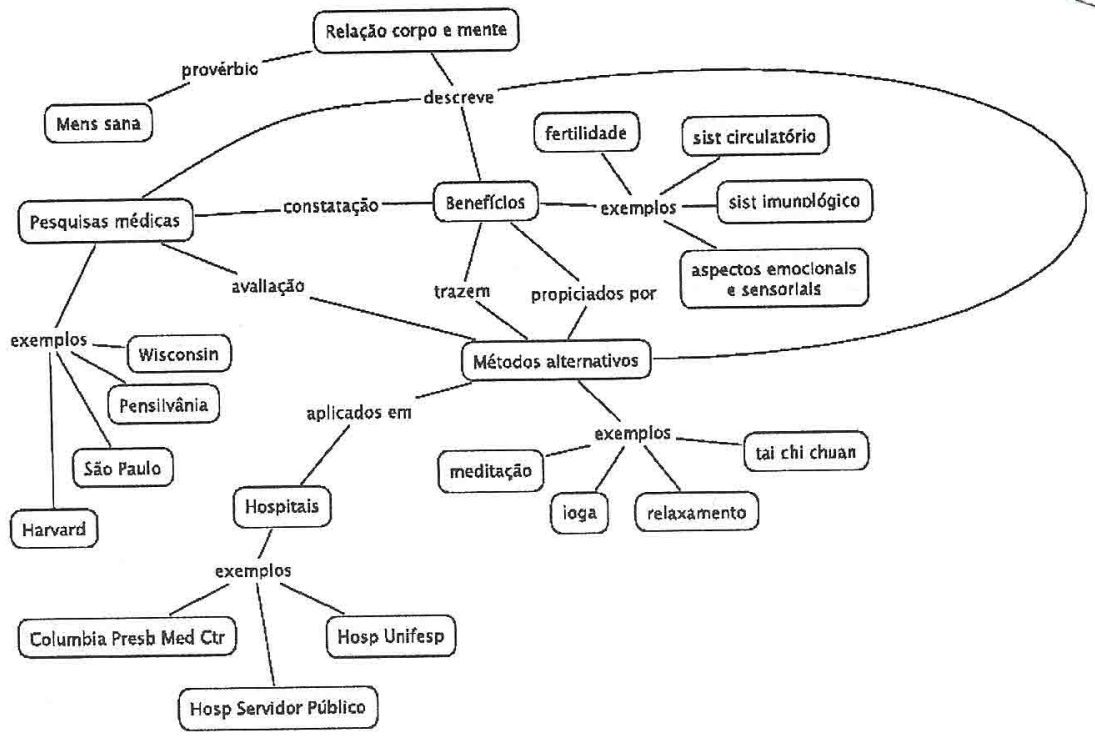

Figura 1: Mapa conceitual com relaçōes entre os segmentos de texto. Os cinco temas centrais identificados pelos autores, aqui denominados Relação corpo e mente, Pesquisas médicas, Beneficios, Métodos alternativos e Hospitais, são representados como nós de conceitos associados. Cada un deles é por sua vez complementado por outros segmentos que detalham exemplificam os conceitos centrais.

Constatamos nesse exercício que uma série de comentários avaliativos do autor da matéria não poderiam ser atrelados aos segmentos, já que tais comentários ficariam deslocados com a quebra do eixo linear coesivo. Por exemplo, numa referência à prática da meditação, a autora aponta, no início de um parágrafo: "É evidente que náo se pretende que uma pessoa comum, que só teve contato com Buda por referências vagas, chegue ao Nirvana ou a algo que o vatha." Essa frase não se adequava de forma natural a nenhum segmento temático e servia como a ponte entre o parágrafo apresentado no exemplo anterior - no qual meditação era definida - e outro, no qual os seus benefícios eram apresentados. Na estrutura de texto não-linear, essa ponte estava quebrada e não fazia sentido incorporála a um segmento. 
BRAGA, Denise B. \& Ricarte, Ivan L.M. Letramento na era digital: construindo...

Outra constatação verificada foi que ambos os pesquisadores, intuitivamente, buscaram segmentar o texto tendo em mente possíveis caminhos de leitura. A operação inicial em direção a esses caminhos é o estabelecimento de associações entre os segmentos criados. No exemplo dado sobre a divisão do parágrafo em três segmentos, há uma associação clara do segundo para o primeiro segmento: o leitor que atinge o segundo segmento (estudos terapêuticos) e ainda não sabe quem é Benson pode desejar ler o primeiro segmento. Também há uma associação do segundo para o terceiro segmento (descrição da técnica), para o leitor que desejar saber o que é meditação. No entanto, não há nenhuma associação direta entre o primeiro e o terceiro segmentos (apresentação do pesquisador Benson e descrição da técnica de meditação).

A determinação de caminhos de leitura é uma outra operação necessária no processo de retextualização. Esses caminhos foram definidos, em nosso exercício, através de uma projeção de possiveis interesses ou objetivos de leitura que poderiam direcionar a navegação de usuários da Internet para as informações que estariamos disponibilizando. Foram assim projetados os seguintes objetivos de leitura: interesse específico na relação corpo e mente, interesse em medicina alternativa, interesse nas técnicas orientais discutidas, e interesse na cura de uma das doenças discutidas no texto. Por exemplo, usando o mapa conceitual da figura 1 como referência, um leitor poderia realizar uma leitura do texto partindo do segmento relação corpo e mente, passando por pesquisas médicas e Wisconsin, voltando a pesquisas médicas e passando a beneficios e concluindo com aspectos emocionais e sensoriais. Esse leitor, por falta de interesse ou por conhecer bem o assunto, não se ateve à leitura de métodos alternativos. Jâ outro leitor poderia ter alcançado o mesmo texto através de uma busca que o levasse a sistemas circulatórios, daí a beneficios propiciados por métodos alternativos, verificasse quais pesquisas médicas avaliaram esses métodos e então buscasse hospitais onde as terapias alternativas fossem aplicadas. 
Rev. ANPOLI, no 18, p. 59-82, jan./jun. 2005.

Tomadas essas decisões, ainda no plano da linguagem, relativas à construção de segmentos - relação entre informação e definição de caminhos de leitura -, o processo de retextualização precisou passar pela fase final de implementação, agora diretamente dependente das linguagens técnicas que geram a interface, estabelecendo uma relação do usuário com um conjunto de arquivos e relações entre arquivos pré-definidos no processo inicial da construção do hipertexto.

\subsection{Considerações técnicas sobre a construção de hipertextos}

Uma vez definidos os conteúdos dos segmentos e as possíveis associações que irão determinar as possiveis leituras do hipertexto, é preciso instanciar uma concretização desse hipertexto através da sua expressão na linguagem técnica. Esse passo é necessário para viabilizar a interação usuário/máquina ou máquina/máquina. As linguagens técnicas mais utilizadas nesse processo são: HTML, XML e CSS. Nesta seção estaremos adotando a linguagem HTML e CSS para ilustrar algumas dessas possibilidades. ${ }^{2}$

Do ponto de vista técnico, o primeiro passo na construção do hipertexto é a criação dos arquivos de texto contendo cada um dos segmentos que foram identificados. Ao tornar disponivel em um arquivo separado cada segmento textual, o autor estará possibilitando que cada segmento seja manipulado independentemente. No vocabulário técnico da Internet, cada segmento é um recurso. Cada um dos arquivos (ou recurso) pode ser identificado e referenciado indivi-

2 Optamos pela linguagem HTML, embora, do ponto de vista técnico, a XML ofereça uma gama mais ampla de recursos para esse tipo de construção textual. O principal motivo para tal escolha é demonstrar que o uso adequado desses recursos não depende das novas tecnologias, como é o caso de XML, ainda não amplamente suportadas pelos navegadores da WWW. No entanto, toda a discussão aqui presente sobre os recursos de HTML aplicar-se-ia igualmente caso a linguagem XML tivesse sido adotada. 
Braga, Denise B. \& Ricarte, Ivan L.M. Letramento na era digital: construindo...

dualmente a partir de outros arquivos, o que permite que um arquivo seja o destino dos links previstos pelo processo de composição do hipertexto.

Para que não haja conflitos de comunicação com a máquina, o conteúdo do arquivo, descrito na linguagem técnica, precisa seguir as normas da gramática de HTML. Essa gramática permite que os arquivos sejam reconhecidos pela máquina e possam, assim, ser apresentados a um leitor através de um navegador WWW (Internet Explorer, Netscape ou Mozilla). HTML é uma linguagem de marcação (markup language). Em outras palavras, além do texto que visualizamos na tela do navegador há outras informações (geralmente ocultas) que são interpretadas pela máquina e que são expressas na forma de marcas agregadas ao conteúdo. Por exemplo, para indicar que uma parte do texto constitui um parágrafo, as marcas $\langle p\rangle$ e $\langle/ p\rangle$ são usadas para delimitar os limites previstos para o parágrafo. $O$ fragmento a seguir ilustra o conteúdo de um arquivo HTML básico:

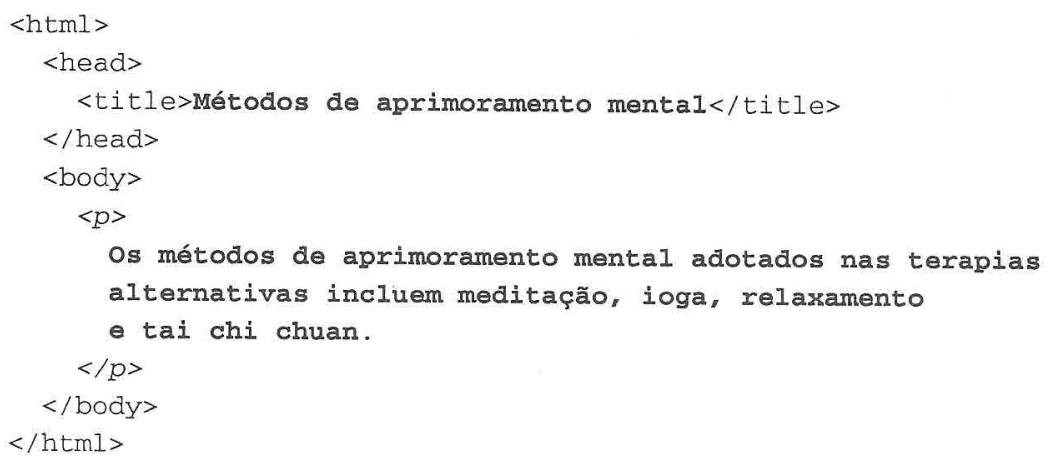

Nas linguagens de marcação, as marcas definem elementos. Assim, nesse arquivo está registrado que há um elemento html (tipo do arquivo em questão). Esse elemento, por sua vez, é composto por dois elementos head e body, que fazem a mediação entre o usuário e a máquina. Mais especificamente, o elemento head contém infor- 
Rev. ANPOLL, n ${ }^{0} 18$, p. 59-82, jan./jun. 2005.

mação que será usada pela máquina, e o elemento body contém a informação que será apresentada ao usuário. Nesse exemplo, o único conteúdo do elemento head é o elemento title, que define o texto que irá aparecer na barra de títulos do navegador. Já o elementó body também tem um único elemento, $p$, com o texto do parágrafo que será apresentado na tela do navegador.

Considerando a geração de hipertextos, um dos principais elementos de HTML a serem considerados é o elemento de âncora, definido pela marca $a$. Uma âncora é cada um dos dois extremos de um link. Implicitamente, todo arquivo HTML tem uma âncora de destino associada ao início do arquivo e, portanto, a definição desse tipo de âncora pode ser omitida. Já as âncoras de origem da hiperligação devem ser marcadas explicitamente no texto. Por exemplo, para estabelecer a ligação do texto acima (métodos de aprimoramento mental) com a definição de meditação, que foi criada em outro arquivo, foi preciso incluir as marcas da âncora em torno do texto selecionado para ativar esse link, como ilustra o exemplo que segue:

... incluem <a href="meditacao.html">meditação</a>, ioga, ...

Explicando em mais detalhes o exemplo, a marca de início do elemento de âncora contém a especificação de uma propriedade (href) cujo valor indica qual o recurso (nome do arquivo) que será utilizado caso o usuário ative este link durante a navegação. Se o usuário de fato ativar esse link, o arquivo indicado será transferido para a máquina do usuário e apresentado no navegador.

Para os autores de hipertexto, outra característica relevante da linguagem HTML é o fato de que ela não determina como os elementos devem aparecer para o usuário, ou seja, um arquivo em HTML determina a estrutura, mas não o formato de apresentação. Para hipertextos simples, é comum o autor simplesmente aceitar que o leitor visualize sua obra através da especificação de apresentação que é definida implicitamente pela máquina, na configuração 
Braga, Denise B. \& RicARTE, Ivan L.M. Letramento na era digital: construindo...

do navegador WWW. No entanto, o autor pode também indicar qual é a forma de apresentação que ele deseja para o seu texto. Para tanto, é possivel associar ao arquivo HTML uma folha de estilo.

Especificações de estilo são descritas em uma outra linguagem, CSS, compreendida pela máquina. Nessa linguagem é possivel associar, para cada elemento de HTML, as preferências de apresentação, tais como cor, fonte e tamanho de um texto. O uso dessa linguagem permite, por exemplo, alterar a cor dos links, um recurso que pode orientar o leitor durante a navegação pelo hipertexto. $\hat{\mathrm{E}}$ possivel determinar, por exemplo, que o texto de uma âncora (ou link) de hipertexto deve ser apresentado com um tom de azul mais suave (teal), sem ser sublinhado e, após visitado, deve ser apresentado em cinza. Para que essa escolha apareça na tela, a seguinte especificação de estilo pode ser usada:

\section{a:link \{color: teal ; text-decoration: none \} \\ a:visited \{ color: grey ; text-decoration: none \}}

Uma das possibilidades interessantes introduzidas pelas folhas de estilo é podermos não só estabelecer ligações entre informações, mas também classificar pela cor o tipo de informação que está sṣndo disponibilizado. É possivel, por exemplo, diferenciar os links que dão acesso a segmentos centrais do hipertexto de outros que trazem informações adicionais, como a visão de algum estudioso sobre o assunto tratado. Esse segundo tipo de link seria diferenciado na definição da âncora através de uma propriedade class, que recebe o nome da categoria criada pelo autor. Por exemplo, se o autor cria essa categoria “quem", então uma âncora desse tipo seria definida da seguinte forma:

$$
\text { ..., diz <a class=' 'quem' href=' 'leite.html' '>Leite</a>. }
$$

O conjunto de exemplos apresentado nesta seção não tem como meta oferecer uma visão aprofundada sobre as linguagens de programação. No entanto, mesmo sendo uma visão genérica, ela pode 
Rev. ANPOLL, no 18, p. 59-82, jan./jun. 2005.

ser útil para entendermos o tipo de escolhas que as linguagens de marcação oferecem para os técnicos. Esse entendimento é necessário para que compreendamos como a interação mediada por computador, principalmente via Internet, é organizada a partir de uma estrutura complexa, planejada em detalhes pelas equipes de designers, e nem sempre evidentes para os usuários.

\section{A construção da cultura na era da Internet: a intermediação têcnica invisivel na tela}

Como ilustra a experiência de retextualização relatada anteriormente, os diferentes caminhos de leitura oferecidos pelo hipertexto são produtos de escolhas e hierarquizações tanto no nivel do sentido quanto no nivel da estruturação técnica. Ao contrário do que acontece com a escrita, a produção de textos digitais não se faz de forma direta, ou seja, é necessário que o autor recorra a linguagens técnicas capazes de "traduzir" suas escolhas de sentido em comandos para os componentes eletrônicos responsáveis pela geração da interface. Como o domínio dessas linguagens de programação demanda um alto grau de especialização, a grande maioria dos usuários recorre a programas de autoria pré-construídos e precisam, portanto, ajustar suas intenções comunicativas às opções de padrão e formato textual oferecidas por esses programas. Além disso, nem o acesso aos hipertextos nem suas leituras ocorrem de forma direta. A interação do usuário/leitor com bancos de dados é diretamente mediada por uma interface técnica que permite algumas possibilidades de consulta e exclui outras. Ponderando sobre essas questões, Walton (2004) sugere que os novos letramentos precisam considerar, de forma mais cuidadosa, o que está por detrás da tela: o campo dos programadores e designers que desenvolvem as linguagens técnicas e os sistemas de categorização utilizados na comunicação via rede. 
Braga, Denise B. \& Ricarte, Ivan L.M. Letramento na era digital: construindo...

Esse tipo novo de comunicação tem um impacto na forma como organizamos nossas realidades e fazemos sentido do mundo em que vivemos. Manovich (2001) chega mesmo a sugerir que, nesse contexto de mudanças, a narrativa deixa de ser a forma privilegiada de expressão cultural. Ou seja, os objetos culturais gerados no meio digital não contam mais histórias que têm começo, meio e fim ou possuem um desenvolvimento temático ou formal que organize seus constituintes em uma seqüência dada. Em vez disso, tais objetos apresentam-se como coleções de itens individuais de dados, estruturados de modo a maximizar sua busca e recuperação através de computadores. Segundo o autor, essa nova forma de cultura modela o mundo através de classificações e categorizações que tipifica a lógica dos bancos de dados. Como salienta Snyder (1996), ao contrário das narrativas, que criam uma trajetória de causa e efeito, o banco de dados apresenta-se aos usuários como um sistema de categorização potencialmente poderoso, que oferece um conjunto de opções para escolha e visualização de grupos de dados (itens de informação).

Discutindo a interação de usuários com textos na Internet, Walton chama a atenção para o fato de que a rede é simultaneamente um artefato de composição visual e um conjunto de dados bastante caótico. A composição é uma característica chave da cultura do computador, na medida em que ela permite ligar um conjunto de elementos isolados e criar um artefato visual que agrega sentidos lingüisticos, visuais, sonoros, gestuais e espaciais sem que tal integração aparente ter suturas. Esse sistema de organização subjacente, nem sempre visivel para os usuários do computador e da Internet, orienta tanto a leitura de hipertextos isolados quanto as consultas aos sites da Internet (Braga, 2003; Walton, 2004).

Considerando questões pertinentes à pesquisa em rede, Walton ressalta que mesmo as ferramentas de busca, um dos principais caminhos utilizados para o acesso à vasta coleção de fontes informativas disponibilizadas na Internet, seguem sistemas prê-definidos de organização de listas, que podem variar de ferramenta para 
Rev. ANPOLL, $\mathrm{n}^{0} 18$, p. 59-82, jan./jun. 2005.

ferramenta e também produzir resultados que são conflitantes com a lógica privilegiada por diferentes usuários. Como coloca a autora, o método adotado pelo Google promove sites que recebem mais referência em outros sites, o que pode oferecer um certo parâmetro para avaliar a "autoridade" dos sites listados. Outras ferramentas promovem sites por razões meramente comerciais. Alguns usuários podem não estabelecer distinções entre diferentes resultados de busca ou não perceber que os links de patrocinadores colocados na tela são na realidade formas veladas de comerciais.

Outro problema apontado por Walton é o de que os termos selecionados pelos usuários para conduzir as pesquisas podem não coincidir com aqueles previstos pelos construtores das ferramentas de busca. Poderiamos dizer que esse problema, na realidade, é de natureza semelhante àquele enfrentado por leitores na consulta das páginas amarelas dos catálogos telefônicos. A imaterialidade da informação na rede, no entanto, tende a tornar esse tipo de problema muito mais sério, já que o leitor não tem acesso ao todo.

Uma outra questão levantada por Walton que nos ajuda a entender possiveis problemas de consulta à rede, está relacionada à própria organização dos diferentes sites. Um site, assim como o hipertexto isolado, prevê uma arquitetura para informação composta por mapas e diretórios hierarquizados. Como toda situação de construção textual, essas organizações orientam-se por modelos de mundo e de possiveis leitores, ambos culturalmente marcados. Essa é uma questão que talvez precise ser considerada por aqueles que entendem a leitura de hipertexto como sendo totalmente controlada e determinada pelo leitor.

\section{Prâticas de leitura na Internet: consideraçōes so- bre a formação do hiper-leitor}

O hipertexto surge como um produto de avanços tecnológicos que permitiram a ligação e a recuperação ágil de arquivos de infor- 
BragA, Denise B. \& RICARTE, Ivan L.M. Letramento na era digital: construindo...

mação. A expansão do uso de banco de dados vem em resposta a demandas sociais específicas que mobilizam um saber novo e multiplicam a memória da escrita, exposta agora na tela. O volume e a diversidade de informações que circulam na atualidade exigem formas mais rápidas de armazenamento, consulta e contraste de dados, o que gera mudanças na natureza do letramento, jâ que há uma alteração significativa nos modos de produção e leitura de textos e na inserção dessas atividades nas práticas sociais cotidianas. As possibilidades técnicas de organização e recuperação de arquivos, discutidas anteriormente, afetam diretamente a leitura. A leitura de hipertexto difere da leitura de textos impressos, na medida em que demanda o desenvolvimento de habilidades e estratégias específicas para o meio digital. Algumas dessas habilidades e estratégias não surgem necessariamente nesse meio, e talvez migrem da experiência prévia dos leitores com textos escritos (Burvulles e Callister, 2000), no entanto, a passagem de um meio para outro exige adaptações: estratégias letradas tradicionais, quando incorporadas às praticas digitas, ganham um nivel de complexidade e sofisticação maior. Alguns exemplos talvez sejam úteis para ilustrar essas mudanças.

A compreensão na leitura de textos escritos não pode ocorrer sem que haja um conjunto de inferências na construção do sentido (Braga, 1990). Algumas vezes a leitura do texto exige que o leitor recupere, do contexto, as marcas de coesão ou relação lógica entre as idéias, deixadas implícitas pelo autor. Na interação com o hipertexto, o leitor deixa de contar com o apoio da linearidade e do eixo argumentativo textual, que oferecem um co-texto para sua leitura. É necessário, portanto, que esse leitor construa uma coesão e uma estrutura lógica que integre e confira sentido aos diferentes fragmentos textuais lidos. Esse tipo de prática pode ser semelhante àquela que já ocorre na leitura para pesquisa, quando os leitores consultam diversas fontes simultaneamente. A diferença, no entanto, é que, no caso de hipertextos, o texto em sua totalidade não 
Rev. ANPOLL, n 18, p. 59-82, jan./jun. 2005.

permanece disponivel para possiveis consultas do leitor. Acessar informações de forma fragmentada e construir sentidos a partir desses segmentos deixa de ser uma opção do leitor e passa a ser uma demanda da leitura, esta, de agora em diante, tributária de dispositivos técnicos outros.

Outro ponto a ser considerado é a necessidade do desenvolvimento de estratégias sofisticadas de exploração geral e rápida do texto (scanning strategies) e de localização de informação específica (skimming strategies). Essas estratégias são necessárias para encontrar a informação procurada e também para descartar textos não relevantes. É inviável que o leitor leia em detalhes todo o material que lhe é oferecido nas suas diferentes incursões de busca. Na realidade, o volume de informação disponivel em rede pode por vezes ser um fator que desnorteia o leitor e dificulta a definição ou a manutenção de um foco específico para a leitura. Como colocam Callister e Burbulles (2000), aprendizes pouco familiarizados com áreas especificas de conhecimento podem facilmente ficar à deriva no mar de informações disponibilizados em rede. Esses alunos precisam de orientações prévias que restrinjam seu escopo de leitura. Isso é valido também para uso de CDROMs educacionais, quando estes integram volumes de informação muito grande.

Focalizando dificuldades encontradas no estudo em rede, Walton (op.cit.) reitera que bases de dados mais amplas recompensam o leitor que é capaz de identificar o grau de especificidade adequado para a sua pesquisa. Essa especificidade pode às vezes ser obtida colocando um conjunto de termos entre aspas. Esse recurso faz com que as ferramentas de busca entendam a pesquisa como uma "frase", o que pode diminuir a chance de indicações não pertinentes. No meio digital, o leitor precisa sempre ter em mente que as ferramentas de busca não "compreendem" documentos, elas simplesmente recuperam de forma mecânica alguns endereços da rede e criam listas a partir de padrões de mapeamento pré-estabelecidos. Cabe ao usuário fazer escolha entre os itens listados, uma tarefa 
BRAgA, Denise B. \& Ricarte, Ivan L.M. Letramento na era digital: construindo...

que depende tanto do nível e da fluência na lingua adotada pelo site, quanto do conhecimento discursivo.

Como ilustra Walton, quando confrontados com a indicação dos endereços que seguem, leitores experientes são capazes de fazer algumas predições sobre o sentido e a relevância das informações apresentadas.

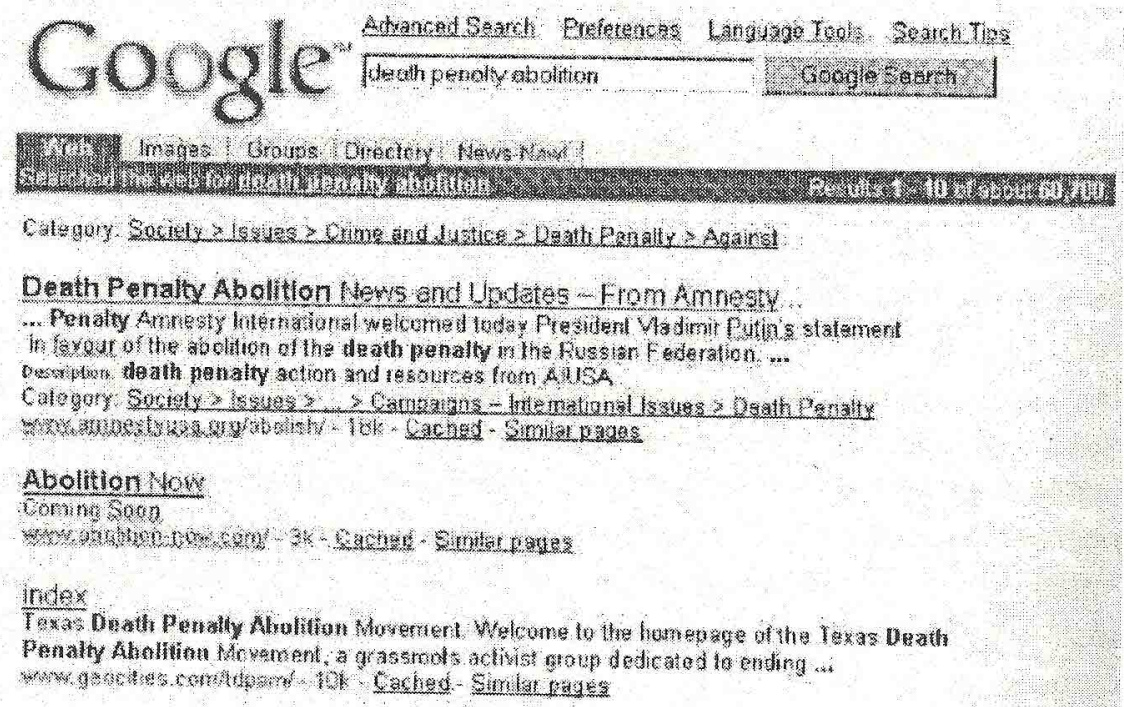

Figura 2: Imagem apresentada em Walton 2004 para ilustrar consultas ao Groogle.

Titulos mais descritivos, e que contenham metadados (description: "death penalty action and resources from AIUSA"), oferecem parâmetros mais adequados para que o leitor possa avaliar possiveis escolhas de sites. Descrições mais minimalistas aumentam a chance de acesso a conteúdos marginais ao tema da pesquisa. Além disso, como aponta a autora, a escolha de endereços também depende de conhecimento lingüistico e discursivo. Mesmo em niveis mais básicos, a pesquisa em rede demanda uma fluência lingüistica bastante avançada. Esse grau de sofisticação também se aplica ao conhecimento discursivo do leitor. Conhecer o papel de 
Rev. ANPOLL, n ${ }^{0}$ 18, p. 59-82, jan./jun. 2005.

uma organização como a Anistia Internacional, e a posição ideológica que tal organização defende no debate sobre a pena de morte, pode auxiliar o leitor a considerar ou não a escolha desse site.

Outra questão a ser considerada na formação do hiperleitor é o olhar sobre o mundo veiculado pelos diferentes modelos de organização de dados. Como ressalta Braga (2003), ê possivel, através da estrutura dos links, orientar a leitura e privilegiar o destaque de determinadas informações. Perspectivas específicas sobre o mundo também estão implicitas no processo de categorização que estrutura os sites e portais. Considerando que o usuário ou grupos de usuários previstos pelos construtores de sites e páginas é sempre uma projeção idealizada, é possivel antevermos que a leitura do material disponibilizado na Internet pode sempre ser afetada por problemas de comunicação. Essa é uma possibilidade relativamente óbvia, quando consideramos que esse material é dirigido à massa de usuários. Outra questão a ser considerada, e essa nem sempre evidente, è a de que Internet é produto e também produtora de concepções específicas sobre a realidade. Como nos instiga Walton:

Os novos letramentos requerem que olhemos cuidadosamente para o que está atrás da tela, para o domínio dos programadores e designers que desenvolvem esquemas de codificação e linguagens, e geram os sistemas de categorização que precisamos usar para nos comunicarmos na rede. Sem esse exame cuidadoso, estaremos à mercê dos grupos que criam as convençōes, os padrōes e as linguagens que dão forma ao que pode ser dito na rede e como isso pode ser feito (Walton, 2004:118 - tradução nossa).

ABSTRACT: The paper discusses digital literacy focusing on issues related to hypertext authoring and reading. An experiment conducted by the authors, aimed at rewriting a linear printed text into a hypertext format is described. The discussion highlights that hypertext interactions demand a development of new reading strategies as well as a deeper understanding of the role that technical mediation has in the process of meaning construction within the digital media. 
BragA, Denise B. \& RICARTE, Ivan L.M. Letramento na era digital: construindo...

KEY WORDS: Digital literacy; hypertext; authoring; reading; digital culture.

\section{Bibliografia}

BRAGA, D.B. (1991) "Selective Focus in Reading: a Social-Based Explanation". Lenguas Modernas, Vol. 18, p. 117-132.

. (2003) "A natureza do hipertexto e suas implicaçōes para a liberdade do leitor e o controle do autor nas interações em ambiente hipermídia". Revista da Anpoll n.15, 65-86.

BraGa, D.B.; Busnardo, J. (2004) "Digital literacies for autonomous learning: Designer problems and learner choices" In: Snyder, I. e Beavis, C (eds) Doing Literacy Online: Teaching, Learning and Playing in an Eletronic World Cresskill, New Jersey: Hampton Press, Inc.

Burbules, N.C.E.; Callister, T.A.Jr. (2000) "Hypertext: Knowledge at the Crossroads". In: Watch It: The Risks and Promises of Information Technologies for Education. Oxford: Westview Press.

KRESS, G. (1998) "Visual and Verbal Modes of Representation in Electronically Mediated Communication: The Potentials of New Forms of Text". In: I. Snyder (org) Page to Screen: Taking Literacy into the Electronic Era New York and London: Routledge.

LANDow, G.P. (1997) Hypertext 2.0: The convergence of contemporary critical theory and technology. Baltimore, London: University Press.

Manovich, L. (2001) The Language of the New Media. Cambridge, Mass. and London: The MIT Press.

Marcuschi, L.A. (2001) Da fala para a escrita: Atividades de retextualização. São Paulo: Cortez

Silva, M. (2000). Sala de Aula Interativa. Rio de Janeiro: Guartet.

SNYDER, I. (1996) Hypertext: The electronic labyrinth. New York: University Press.

Walton, M. (2004) "Behind the Screen: The language of web-design" In: Snyder, I. e Beavis, C (eds) Doing Literacy Online: Teaching, Learning and Playing in an Eletronic World Cresskill, New Jersey: Hampton Press, Inc. 